\title{
Removal of Phosphate Using Red Mud: An Environmentally Hazardous Waste By-Product of Alumina Industry
}

\author{
Shivkumar S. Prajapati, ${ }^{1}$ P. A. Mohamed Najar, ${ }^{2}$ and Vijay M. Tangde ${ }^{3}$ \\ ${ }^{1}$ National Institute of Miner's Health, Wadi, Nagpur 440 023, India \\ ${ }^{2}$ Jawaharlal Nehru Aluminum Research Development and Design Centre, Wadi, Nagpur 440 023, India \\ ${ }^{3}$ Department of Chemistry, Rashtrasant Tukadoji Maharaj Nagpur University, Nagpur 440 033, India \\ Correspondence should be addressed to Vijay M. Tangde; vijaytn6@gmail.com
}

Received 29 April 2016; Accepted 26 July 2016

Academic Editor: Jan Skov Pedersen

Copyright (C) 2016 Shivkumar S. Prajapati et al. This is an open access article distributed under the Creative Commons Attribution License, which permits unrestricted use, distribution, and reproduction in any medium, provided the original work is properly cited.

\begin{abstract}
The industrial waste, bauxite residue generated in the Bayer chemical process of alumina production, commonly known as red mud (RM) has been used as the adsorbent for selective removal of phosphate in aqueous solutions. RM collected from the storage area of alumina industry was characterized by chemical analysis and physical methods such as BET surface area, Scanning Electron Microscopy (SEM), particle size analysis, and X-ray diffraction (XRD) methods. Among the various red mud samples $(0.2-200 \mu)$ studied, the samples treated with $1 \mathrm{M} \mathrm{HCl}$ for $2 \mathrm{~h}$ were found better for the selective adsorption of phosphate in comparison with untreated and heat treated RM samples. The presence of phosphate in the aqueous samples collected after adsorption studies with red mud was determined by standard spectrophotometric procedure using ammonium molybdate and ascorbic acid in nitrate medium at $\lambda_{\max } 880 \mathrm{~nm}$. The studies reported significant adsorption of phosphate on acid treated red mud in comparison with adsorption of phosphate on untreated and heat treated red mud, respectively. The adsorption of phosphate on raw red mud and activated red mud was further investigated with respect to stirring time, $\mathrm{pH}$ of the solution, dose of adsorbent, and varying phosphate concentration. Acid treated RM is observed as an efficient and cost-effective adsorbent for selective removal of phosphate in aqueous solutions.
\end{abstract}

\section{Introduction}

Phosphorus as phosphate ions is one of the important soil elements for living organisms. It is an essential element for plant growth present in most of the biological tissues. However, an excess level of phosphate in water bodies helps the development of photosynthetic algae and toxic cyanobacteria. The industrial growth, household applications, and advances in agricultural research and crop development inadvertently cause the phosphate pollution in the aqueous bodies. In view of its potentially hazardous nature, several methods have been developed to remove excessive phosphate from natural and waste water sources [1-8]. That includes biological removal, precipitation method, ion exchange methods using zeolites, and metal oxides [9-12]. The biological method is of low cost but not effective due to variability in temperature of waste water that would make the execution of this process inaccessible for waste water treatment. Chemical treatments such as alum, lime, and ferric chloride are common precipitants used for phosphate removal but this is cost-ineffective and sludge formation makes this as a tedious method for waste water treatments. Most commercial systems currently use activated carbon as sorbent for removal of dyes in waste water because of excellent adsorption ability. However, the involved high cost restricts its widespread use. In the recent years, considerable attention has been paid based on economic and environmental concern to the study of using different types of low cost sorbents such as alum sludge, red mud (RM), fly ash (FA) [8-14], and other waste materials as alternative adsorbents for sorption [15] of phosphate from water.

In the present study, we have used red mud as an effective adsorbent for the removal of phosphates from aqueous solution. Bauxite residue, red mud, is the major solid waste produced during alkaline leaching of bauxite in the Bayer process. It is known to be a potential toxic waste causing serious 
environmental problems due to high alkalinity with $\mathrm{pH} 10-$ 12 and bulk volume. Redness of red mud is mainly due to the presence of iron impurities and chemical analysis of red mud shows silica, aluminium, iron, calcium, titanium, and sodium as major components and other elements such as $\mathrm{K}, \mathrm{Cr}, \mathrm{V}, \mathrm{Ba}, \mathrm{Cu}, \mathrm{Mn}, \mathrm{Pb}, \mathrm{Zn}, \mathrm{P}, \mathrm{F}, \mathrm{S}$, and $\mathrm{As}$ as minor components depending on origin of bauxite mines. For every tonne of alumina produced, approximately 1 to 2 tonnes (dry weight) of red mud residue are generated [8]. Because of the increasing demand for alumina during economic development, more and more RM is being produced. It is estimated that about 90 million tonnes of RM is produced annually on earth, while this is expected to increase by several times in the near future. Due to the alkaline nature and high volume of red mud, it is a serious ecological threat and proper disposal of the waste red mud presents a huge challenge for alumina industries. Many attempts have been made over past years to find some practical applications for red mud such as an additive pigment for mortar and concrete [16, 17] and surface treatment of carbon steel and many investigations have also been extended to develop red mud as an adsorbent to remove arsenate [18-20], toxic heavy metals [21-28], dyes $[29,30]$, methylene blue [31, 32], and phenols [31-35].

For phosphate removal, some investigators have used either acid or heat treated RM as adsorbent $[2,8]$. Shiao and Akashi [1] reported adsorption of phosphate from aqueous solution using $\mathrm{HCl}$ activated red mud and achieved 80$90 \%$ removal efficiency. Studies have also been reported by Aitundogan and Tumen [4] in which the sample prepared by using red mud stirred with $\mathrm{HCl}$ for $2 \mathrm{~h}$ as well as another sample prepared by heating $\mathrm{RM}$ at $700^{\circ} \mathrm{C}$ for $2 \mathrm{~h}$ results in the maximum removal of phosphate (99\% removal of phosphate). It is seen that acid or heat treatment could produce an effect on phosphate adsorption depending on the material and treatment conditions.

In this paper, we report the spectroscopic characterization and investigation of the adsorption studies on raw and activated red mud for phosphate removal from aqueous solution. We have investigated the effect on morphology and adsorptive behaviour of the modified red mud by heat and acid treatment. This is done with the help of BET surface analyser, particle size analyser, X-ray diffraction, and Scanning Electron Microscopy.

\section{Experimental}

2.1. Materials. The raw red mud sample used in the present study was provided by the National Aluminium Company Ltd., Damanjodi, Orissa, India. The chemical composition of raw material was determined by the wet chemical analysis method and chemical compositions of the red mud based on dry weight are $\mathrm{Fe}_{2} \mathrm{O}_{3}$ (54.6\%), $\mathrm{Al}_{2} \mathrm{O}_{3}$ (16.44\%), L.O.I (11.67\%), $\mathrm{TiO}_{2}$ (6.82\%), $\mathrm{SiO}_{2}$ (4.24\%), $\mathrm{Na}_{2} \mathrm{O}$ (2.76\%), and $\mathrm{CaO}(1.99 \%)$. This raw red mud was washed several times with deionised water and hereafter referred to as red mud (RM). Initially these RM samples were calcined in a muffle furnace at $700^{\circ} \mathrm{C}$ in air for $2 \mathrm{~h}$. This is referred to as red mud heated $(\mathrm{RMH})$ sample. The other RM samples were mixed with $1 \mathrm{M} \mathrm{HCl}$ for $24 \mathrm{~h}$ at liquid/solid ratio of $20 \mathrm{~mL} / \mathrm{g}$.
These samples are referred to as acid treated RM-HCl (RMA). After acid treatment, the RMA was washed once again with deionised water and dried overnight at $105^{\circ} \mathrm{C}$. The acid treated sample of RMA was then calcined in muffle furnace at $700^{\circ} \mathrm{C}$ in air for $2 \mathrm{~h}$. This is referred to as red mud acid heated (RMAH) sample. The resultant solid samples of RMAH were then allowed to cool down overnight in the furnace.

The chemicals and reagent used in this research including hydrochloric acid $(\mathrm{HCl})$, sulphuric acid $\left(\mathrm{H}_{2} \mathrm{SO}_{4}\right)$, ascorbic acid $\left(\mathrm{C}_{6} \mathrm{H}_{8} \mathrm{O}_{6}\right)$, sodium hydroxide $(\mathrm{NaOH})$, potassium dihydrogen phosphate $\left(\mathrm{KH}_{2} \mathrm{PO}_{4}\right)$, ammonium molybdate tetrahydrate $\left[\left(\mathrm{NH}_{4}\right)_{6} \mathrm{Mo}_{7} \mathrm{O}_{24} \cdot 4 \mathrm{H}_{2} \mathrm{O}\right]$, and potassium antimonyl tartrate $\left[\mathrm{K}(\mathrm{SbO}) \mathrm{C}_{4} \mathrm{H}_{4} \mathrm{O}_{6} \cdot 1 / 2 \mathrm{H}_{2} \mathrm{O}\right]$ were of analytical grade, and all the solutions were prepared by using deionised water as solvent.

2.2. Characterization. The prepared red mud samples, RM, $\mathrm{RMH}, \mathrm{RMA}$, and RMAH, were characterized using BET surface analyser, particle size analyser, X-ray diffraction, and Scanning Electron Microscopy. The surface area was obtained by nitrogen-desorption at the liquid nitrogen temperature $\left(-196^{\circ} \mathrm{C}\right)$ using ASAP Micromeritics 2020. All samples were degassed at $200^{\circ} \mathrm{C}$ for $2 \mathrm{~h}$ before analysis. The BET equation was applied to determine the surface areas of RM, RMH, RMA, and RMAH.

$\mathrm{X}$-ray diffraction (XRD) patterns of all samples were measured using an X'pert PRO, Pan Analytical Diffractometer with $\mathrm{Cu} \mathrm{K} \alpha$ radiations generated at $40 \mathrm{kV}, 30 \mathrm{~mA}$. Scattering angles were ranged from 20 to $60^{\circ}$, with a scanning rate of $20^{\circ}$ per minute.

Particle sizes of RM, RMH, RMA, and RMAH samples were analysed using Micromeritics Saturn DigiSizer II 5205 particle size analyser. This data will help us in determining the percentage of particles belonging to particular size category that is attributed to surface area.

Microstructure and surface morphology of the adsorbent samples were characterized by a JSM IT-300 field emission Scanning Electron Microscopy (SEM) with an accelerating voltage of $15 \mathrm{kV}$ at a magnification of $1 \times 10000$.

The thermogravimetric (TG) analysis of RM, RMH, RMA, and RMAH samples was carried out in $\mathrm{N}_{2}$ atmosphere using NETZS 402PC heat analyser at the heating rate of $20^{\circ} \mathrm{C} /$ min ranging from $30^{\circ} \mathrm{C}$ to $1000^{\circ} \mathrm{C}$.

The results obtained from SEM analyses and TGA graphs suggest that some significant phase transformations take place on acid or heat treatment, which is discussed at later stages in the paper.

2.3. Adsorption Studies. Adsorption experiments were conducted by stirring the $20 \mathrm{~mL}$ of varying concentrations of phosphate solution ranging from $50 \mathrm{mg} / \mathrm{L}$ to $1000 \mathrm{mg} / \mathrm{L}$ (prepared by $\mathrm{KH}_{2} \mathrm{PO}_{4}$, phosphate concentration) with $0.1 \mathrm{~g}$ of adsorbent in the capped conical flasks at $30^{\circ} \mathrm{C} \pm 1^{\circ} \mathrm{C}$ for 8 hours. After equilibrium, the clear filtered solutions were obtained using the pulp filtration method and we analysed the phosphate concentration by following the modified single solution method as given by Murphy and Riley [36] and in State Environmental Protection Adminstration [37]. A calibration curve was obtained by measuring the absorbance 
TABLE 1: Chemical analysis of RM (raw red mud), RMH (red mud heated at $700^{\circ} \mathrm{C}$ for $2 \mathrm{hr}$ ), RMA (red mud treated with $1 \mathrm{~N} \mathrm{HCl}$ ), and $\mathrm{RMAH}$ (red mud treated with $1 \mathrm{M} \mathrm{HCl}$ and heated at $700^{\circ} \mathrm{C}$ for $2 \mathrm{hr}$ ).

\begin{tabular}{lccccccc}
\hline Samples & $\mathrm{Al}_{2} \mathrm{O}_{3}(\%)$ & $\mathrm{Fe}_{2} \mathrm{O}_{3}(\%)$ & $\mathrm{SiO}_{2}(\%)$ & L.O.I $(\%)$ & $\mathrm{TiO}_{2}(\%)$ & $\mathrm{Na}_{2} \mathrm{O}(\%)$ & $\mathrm{K}_{2} \mathrm{O}(\%)$ \\
\hline $\mathrm{RM}$ & 16.44 & 54.6 & 4.24 & 11.67 & 6.82 & 2.76 & - \\
$\mathrm{RMH}$ & 16.48 & 63.8 & 4.49 & 3.82 & 7.18 & 1.73 & - \\
$\mathrm{RMA}$ & 15.1 & 61.3 & 1.36 & 11.9 & 8.37 & 0.26 \\
RMAH & 16.5 & 67.5 & 1.42 & 1.62 & 9.5 & 1.7 & 1.63 \\
\hline
\end{tabular}

of phosphate concentration ranging from 0.02 to $0.2 \mathrm{mg}$ of $\mathrm{PO}_{4}{ }^{2-} / \mathrm{L}$ as the basis to determine the concentration of unknown sample with the help of UV-Visible range Shimadzu UV-1800 spectrophotometer at $882 \mathrm{~nm}$ wavelengths. The amount of phosphate adsorbed per unit mass of adsorbent was calculated by

$$
X=\frac{\left(C_{i}-C_{f}\right) * V}{m},
$$

where $X$ is the concentration of the phosphate adsorbed; $C_{i}$ and $C_{f}$ are the initial and final concentrations of the phosphate in $\mathrm{mg} / \mathrm{L} . V$ is the volume in litre of solution taken in a conical flask for stirring whereas $m$ is the weight of adsorbent.

Now, in order to determine the mechanism of adsorption of phosphate on RM, RMH, RMA, and RMAH, Langmuir and Freundlich isotherms were applied to describe the equilibrium adsorption of solute from solution at constant temperature. Langmuir isotherm assumes the sorption process at specific homogeneous site for monolayer adsorption. The Langmuir isotherm can be expressed as

$$
X=\frac{k X_{m} C_{\mathrm{eq}}}{1+k C_{\mathrm{eq}}},
$$

where $X$ is the adsorbed amount of the solute in $\mathrm{mg}$ of $\mathrm{PO}_{4}{ }^{2-} / \mathrm{g}$ of adsorbent, $C_{\mathrm{eq}}$ is the equilibrium concentration of the solution in $\mathrm{mg}$ of $\mathrm{PO}_{4}{ }^{2-} / \mathrm{L}, X_{m}$ is the monolayer adsorption capacity $(\mathrm{mg} / \mathrm{g})$, and $k$ is a constant related to the free energy of adsorption. The Freundlich adsorption isotherm is an empirical relation used to describe heterogeneous system which can be expressed as

$$
Q=K C_{\mathrm{eq}}^{1 / n},
$$

where $K$ is a constant that indicates the extent of the adsorption and $n$ is a constant that indicates the nonlinearity between concentration and the extent of adsorption at the experimental pressure as given by Dursun et al. [8].

\section{Results and Discussion}

3.1. Chemical Analysis of Red Mud. Chemical analysis of raw and activated red mud shows the distinct variation in their chemical composition (Table 1). Variation in chemical composition of various samples of RM is attributed to their adsorption capacity. Specifically, Loss On Ignition (LOI) data show significant decrease in LOI in case of heat action that

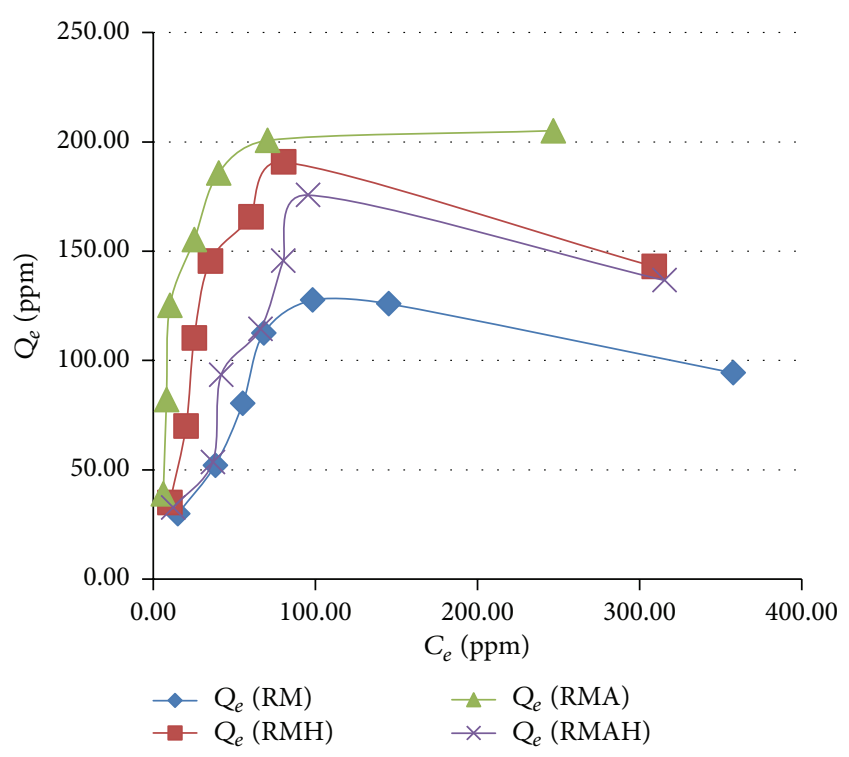

FIGURE 1: Adsorption isotherm showing effect of equilibrium concentration on phosphate removal using RM, RMH, RMA, and RMAH.

is reflected in increased concentration of iron oxides. This is attributed to the increased adsorption capacity of heat activated red mud.

The acid treated RMA shows higher adsorption compared to $\mathrm{RMH}$ and RMAH. It is also observed from experimental results (Figure 1) that the adsorption capacity of raw red mud can be improved significantly by acid treatment.

3.2. Effect of Stirring Time. The effect of stirring time on the removal of phosphate was studied by varying the time of stirring from $2 \mathrm{hr}$ to $10 \mathrm{hr}$ for the optimum equilibrating time. Results (Figure 2) show that the equilibrium in adsorption of phosphate is attained at about $8 \mathrm{hr}$ of stirring time in case of RM whereas, in case of activated red mud, variation in stirring time does not show any significant effect after $2 \mathrm{hr}$ of stirring. Therefore, for the sake of self-sufficiency, the optimum stirring time of $8 \mathrm{hr}$ has been chosen for all investigations throughout the study.

3.3. Effect of Phosphate Concentration. Adsorption studies were carried out on a fixed weight of red mud with varying phosphate concentrations from 50 to $500 \mathrm{mg} / \mathrm{L}$. It is observed from our studies that the phosphate removal efficiency increases with increasing phosphate concentrations and rises to maxima up to around 250 to $300 \mathrm{mg} / \mathrm{L}$ (Figure 1). Further, 


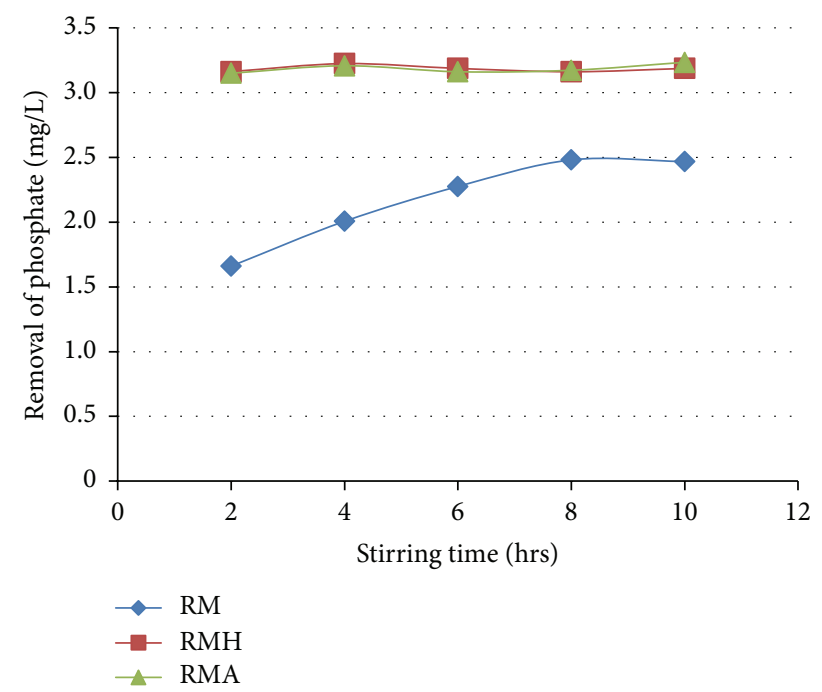

FIGURE 2: Effect of variation of stirring time on removal of phosphate from solution.

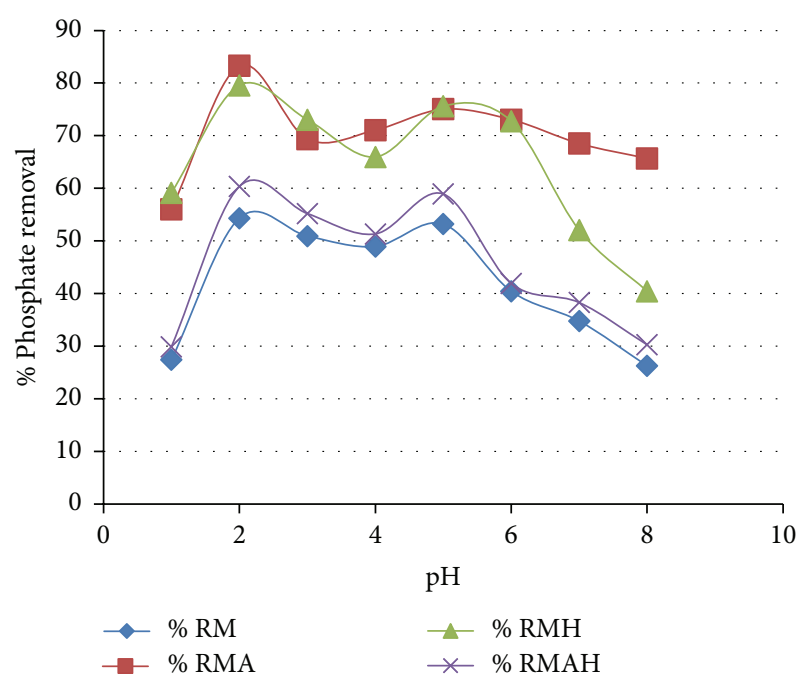

FIGURE 3: Effect of variation in $\mathrm{pH}$ on adsorption of phosphate on RM, RMA, RMH, and RMAH.

it is observed that phosphate removal efficiency does not show any significant change after phosphate concentration of $300 \mathrm{mg} / \mathrm{L}$. Zhao et al. [5] have shown that such behaviour is anticipated due to the buffering properties of phosphate compounds.

3.4. Effect of $p H$. The effect of variation in $\mathrm{pH}$ on the removal of phosphate has also been studied in the range from 1.0 to $10 \mathrm{pH}$ of phosphate solution using $0.1 \% \mathrm{HCl}$ and $0.1 \%$ $\mathrm{NaOH}$ solutions that gave the optimum value of $\mathrm{pH}$ for our investigations. It is apparent from Figure 3 that the phosphate removal shows maxima at $\mathrm{pH} 2.0$ of solution and then decreases with further increase in $\mathrm{pH}$ from 3.0 to 10.0. This trend has no exceptions irrespective of RM, RMA, RMH, and RMAH. Significant enhancement of adsorption was achieved at about $\mathrm{pH} 2$ (Figure 3). This is attributed to that fact

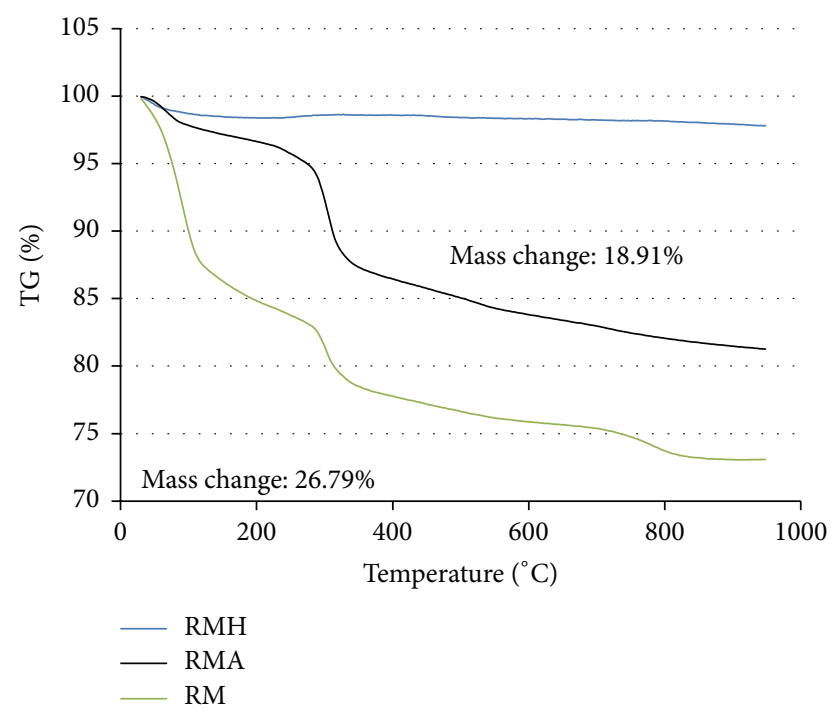

FIgURE 4: Thermogravimetric analysis (TGA) of RM, RMA, and RMH.

that, at higher $\mathrm{pH}$, surface of the red mud carries more negative charges which may serve to increase the repulsion of negatively charged phosphate species in solution and consequently results in lower RM adsorption capacity. These results are in good agreement with the available literature [6].

3.5. Thermal Analysis. Thermal gravimetric analysis of RM (Figure 4) shows a continuous weight loss distributed over the range of $30-900^{\circ} \mathrm{C}$. Composition of RM mainly contains crystalline hematite $\left(\mathrm{Fe}_{2} \mathrm{O}_{3}\right)$, boehmite (gamma$\left.\mathrm{Al}_{2} \mathrm{O}_{3} \cdot \mathrm{H}_{2} \mathrm{O}\right)$, quartz $\left(\mathrm{SiO}_{2}\right)$ with minor percentage of calcite $\left(\mathrm{CaCO}_{3}\right)$, gibbsite $\left(\mathrm{Al}(\mathrm{OH})_{3}\right)$, and other minor components like $\mathrm{Na}_{2} \mathrm{O}, \mathrm{TiO}_{2}, \mathrm{~K}_{2} \mathrm{O}$, and so forth [1]. It is observed from TGA (Figure 4 ) that the total weight loss is $26.79 \%, 19 \%$, and about $2 \%$ in cases of RM, RMA, and RMH, respectively.

Further, the corresponding total weight loss in case of RM (Figure 5(a)) can be classified into three major stages, namely, the initial weight loss of $15.68 \%$ between 30 and $220^{\circ} \mathrm{C}$. This is attributed to the evaporation of moisture adsorbed on the surface of powdered RM. The subsequent weight loss of $6.47 \%$ in the range from 220 to $400^{\circ} \mathrm{C}$ is due to the release of constituent water from crystals in the minerals, such as boehmite and gibbsite, and the final weight loss of $4.63 \%$ may be attributed to the decomposition of calcite and whewellite [2] and after that almost remains constant. In case of RMA (Figure 5(b)), the major loss appears to be in the range of 200 to $500^{\circ} \mathrm{C}$ that may be attributed to the loss of salts that might have formed during neutralization reaction of acid treatment along with hydrated water.

3.6. XRD Analysis. The crystalline phases of red mud samples were analysed by XRD patterns. In RM (Figure 6(a)), the major phases are gibbsite, hematite, goethite, sodalities, and calcite. The XRD patterns show remarkable changes between RM, RMA, RMH, and RMAH (Figures 6(a), 6(b), 6(c), and 


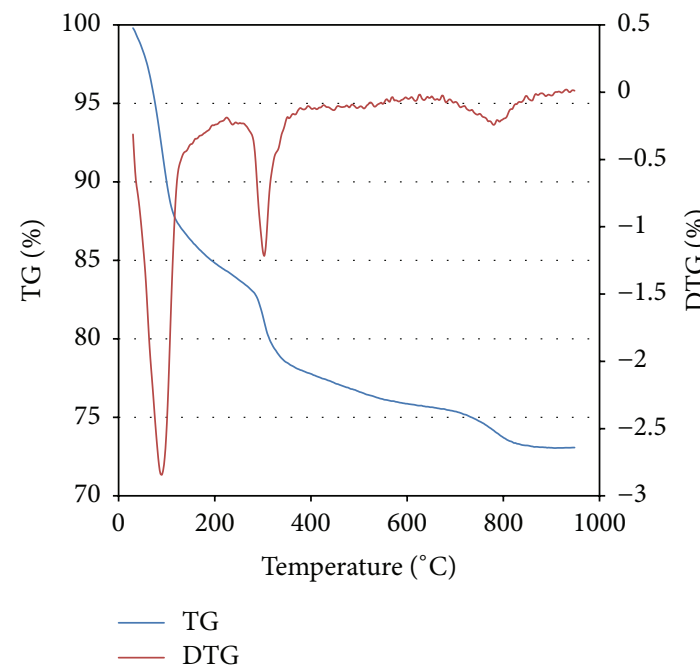

(a)

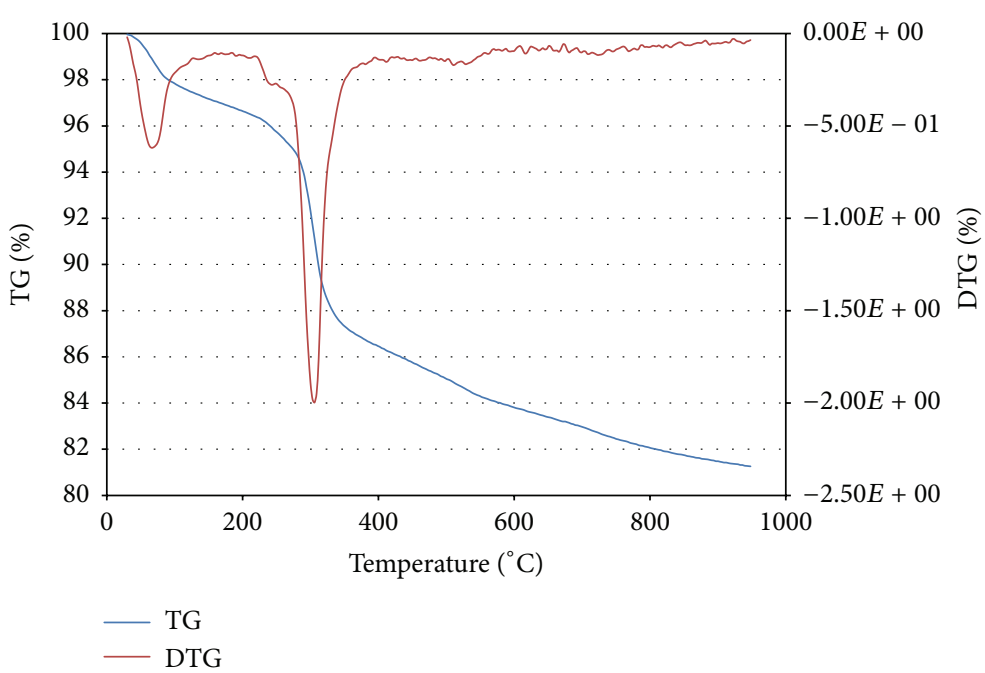

(b)

FIGURE 5: (a) Derivative thermogravimetric (DTG) analysis of RM. (b) Derivative thermogravimetric (DTG) analysis of RMA.

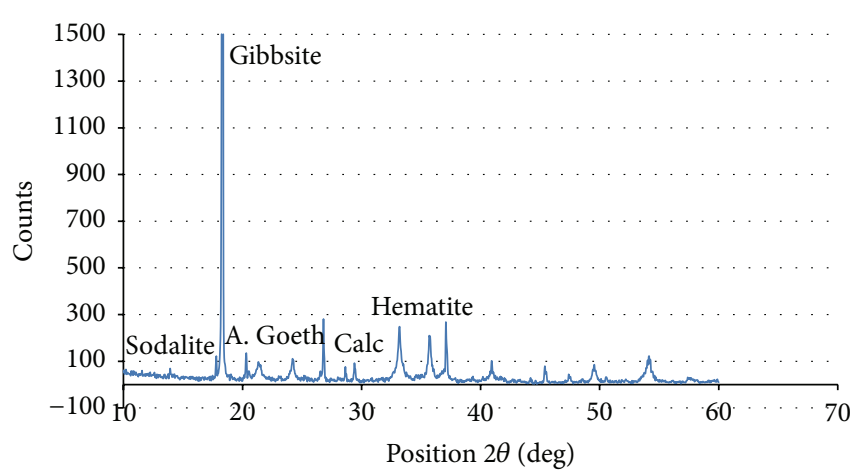

(a)

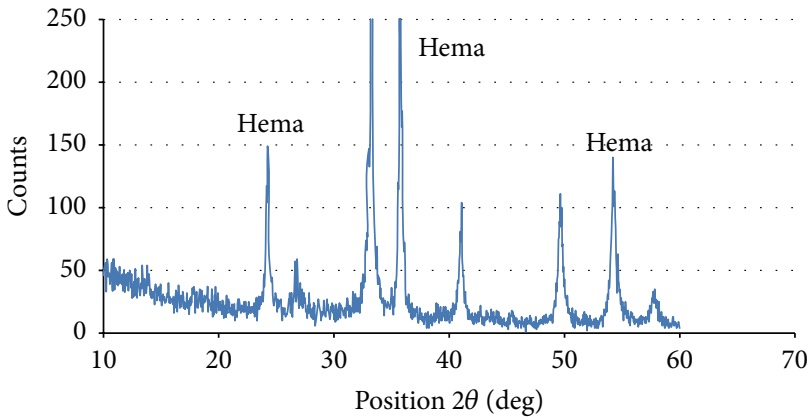

(c)

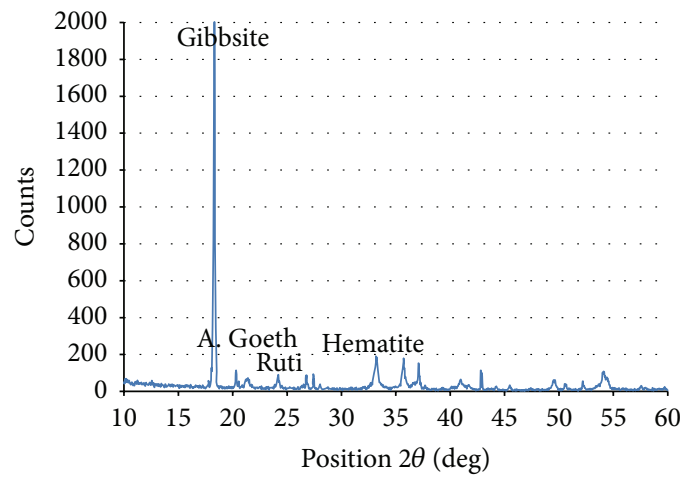

(b)

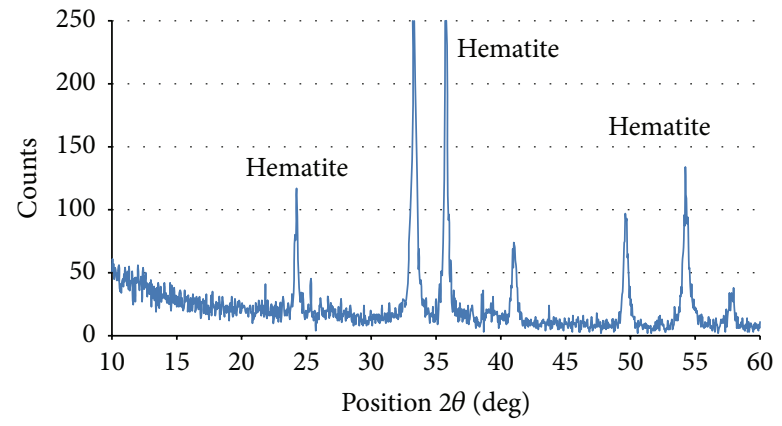

(d)

FIGURE 6: (a) XRD pattern of RM. (b) XRD pattern of RMA. (c) XRD pattern of RMH. (d) XRD pattern of RMAH.

6(d)) which indicate the occurrence of phase transformations. After acid treatment, all the other phases disappear except gibbsite and hematite (Figure 6(b)). Also acid treatment shows a generation of new phase of rutelite which may be attributed to the decomposition of calcite, whereas heating effect on both samples (RMH and RMAH) cause significant enhancement in intensity of hematite (Figures 6(c) and 6(d)). This is in accordance with the fact that heating process destroys crystalline phase of RM and generates amorphous phase.

3.7. BET Surface Area Analysis. The BET surface area analyses (Table 2) reveal that the RM has a specific surface area of $20.82 \mathrm{~m}^{2} / \mathrm{g}$ whereas heating effect on RM (i.e., RMH) shows a greatest enhancement in the specific surface area up to more than double of its original surface area. On treating RM 
TABLE 2: BET surface area analysis of various red mud samples.

\begin{tabular}{llc}
\hline Sr. number & Samples & Area $\left(\mathrm{m}^{2} / \mathrm{g}\right)$ \\
\hline 1 & RM (raw red mud) & 20.89 \\
2 & RMH (heated red mud at $700^{\circ} \mathrm{C}$ for two hours) & 42.01 \\
3 & RMA (acid treated red mud) & 28.63 \\
4 & RMAH (red mud treated with acid and then heated at $700^{\circ} \mathrm{C}$ for two hours) & 37.34 \\
\hline
\end{tabular}

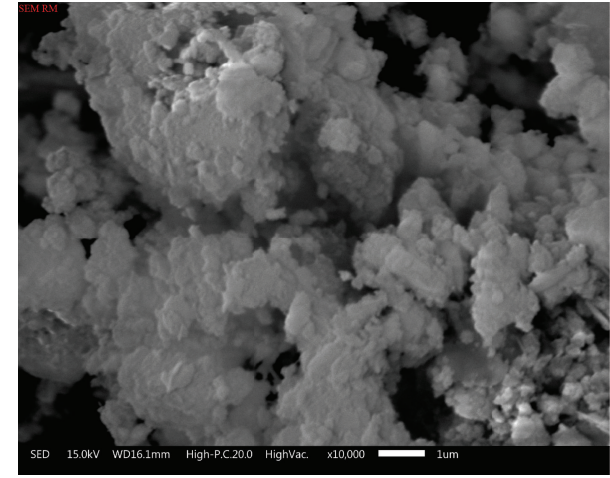

(a)

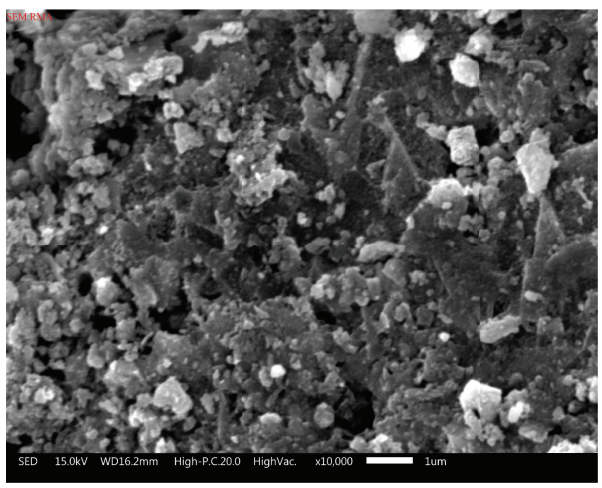

(c)

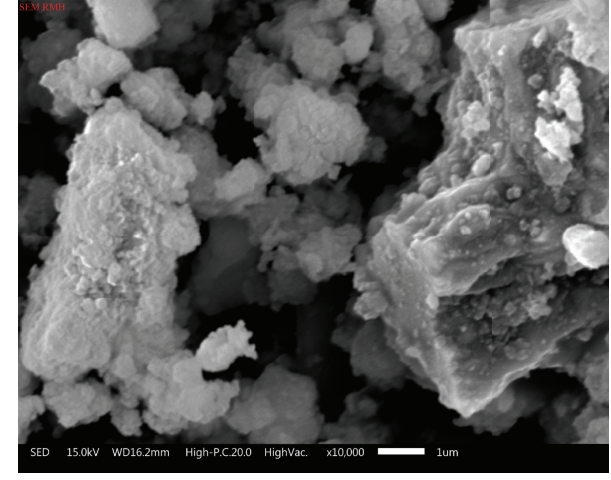

(b)

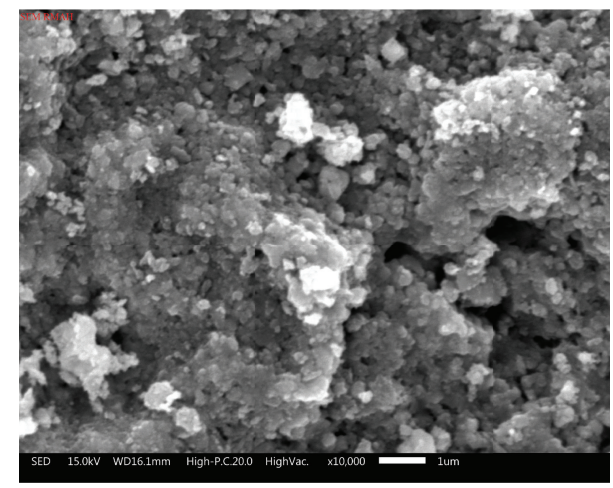

(d)

Figure 7: (a) SEM image of RM. (b) SEM image of RMH. (c) SEM image of RMA. (d) SEM image of RMAH.

with acid (i.e., RMA), surface area increases up to certain significant level of about $40 \%$ but remains lower than that of heated sample. This may be due to the accumulation of some acid soluble fractions like gibbsite, sodalities, goethite, calcite, and some other acid soluble salts [3]. Moreover, heat treatment to RMA sample (i.e., RMAH) again shows significant increase of about $85 \%$ in the surface area. These observations are in strong agreement with the morphological studies in SEM analysis.

3.8. Morphological Analysis. Surface morphological studies of all the RM samples are carried out using SEM images (Figures 7(a), 7(b), 7(c), and 7(d)). Surface of the RM (Figure $7(\mathrm{a})$ ) is relatively smooth and flat in contrast to that of RMH (Figure 7(b)) which gives a clear evidence of generation of new porous surface due to removal of moisture and constituent water from crystals in the minerals, such as boehmite and gibbsite, and due to the decomposition of calcite and whewellite. This is in strong agreement with the BET surface area analysis wherein surface area has been sharply increased almost more than double the original surface area. Acid treatment usually leads to formation of additional new cavities during the acidification process by strong acid which significantly enhances the surface area. The SEM image (Figure 7(c)) of acid treated samples shows many such new cavities along with coarse exterior due to some acid soluble salts. The generation of new surface area by acidification was observed from the difference between the SEM images of Figures 7(a) and 7(c). It is also interesting to see the effect of heat on acid treated sample (Figure $7(d)$ ) because surface area increases more than $85 \%$ from the original surface area which may be attributed to the decomposition of deposited acid soluble fractions like gibbsite, sodalities, goethite, calcite, and some other acid soluble salts. Moreover, on comparing the surface morphology of $\mathrm{RMH}$ and $\mathrm{RMAH}$, it is observed prominently that RMH shows 
higher percentage of cavities leading to higher surface area whereas RMAH shows higher porosity which, however, may not give maximum surface area.

3.9. Adsorption Studies. The sorption studies of phosphate ions on the surface of RM, RMH, RMA, and RMAH were carried out in the concentration range of 50 to $500 \mathrm{mg} \mathrm{P} / \mathrm{L}$. In order to study the mechanism of phosphate adsorption, Langmuir and Freundlich isotherms were applied. The Langmuir adsorption isotherm model represents one of the first theoretical treatments of nonlinear sorption and suggests that the uptake occurs on a homogenous surface by monolayer sorption without interaction between the adsorbed molecules. The Langmuir adsorption isotherm is often used to describe the maximum adsorption capacity of an adsorbent. The phosphate adsorption isotherms (Figure 1) suggest that phosphate adsorption increases with the increases in its concentration up to certain optimum value and reaches a plateau region where no significant enhancement in the adsorption can be obtained.

Among all the four samples of red mud, RMA, in spite of having lower surface area, has achieved adsorption up to $205.1 \mathrm{mg} \mathrm{P} / \mathrm{g}$ of RMA, as compared to RMH and RMAH wherein the maximum adsorption is up to $190.8 \mathrm{mg}$ of $\mathrm{P} / \mathrm{g}$ $\mathrm{RMH}$ and $175.6 \mathrm{mg}$ of $\mathrm{P} / \mathrm{g}$ of RMAH, respectively, whereas it is up to $125.9 \mathrm{mg}$ of $\mathrm{P} / \mathrm{g}$ of RM in case of raw RM. This is due to the fact that phosphate can also form chemisorbed complexes by ligand exchange reactions with hydroxide as suggested by Wang et al. [14]. The hydrolysis of $\mathrm{Fe}^{+3}$ forms $\mathrm{Fe}-\mathrm{OH}$ on the goethite crystals and then phosphate replaces the hydroxyl group and forms a bridge between adjacent $\mathrm{Fe}^{+3}$ as suggested by Atkinson et al. [38]. Also Kim et al. [39] have suggested that the phosphate ions can bind to $\mathrm{Fe}^{+3}$ through two $\mathrm{P}-\mathrm{O}-\mathrm{Fe}$ linkages. Thus, chemisorption due to ion exchange is also an important aspect for the adsorption of phosphate on RMA.

The equilibrium data were analysed in light of the adsorption isotherm models. The data were then fitted to the Langmuir equation as

$$
\frac{C_{\mathrm{eq}}}{X}=\frac{1}{X_{m}}+\frac{1}{k X_{m}} \frac{1}{C_{\mathrm{eq}}},
$$

where $X$ indicates the amount of phosphate adsorbed per unit mass of adsorbent, $C_{\text {eq }}$ is the equilibrium phosphate concentration in solution, $X_{m}$ is the monolayer adsorption, and $k$ is the adsorption constant related to free surface energy. The experimental data of phosphate adsorption on RMA (Figure 8) is plotted using Langmuir equation (4).

The correlation coefficient is found to be 0.99 . All the results show that the Langmuir equation for adsorption fits well. The Langmuir parameters for all the RM samples are summarised in Table 3.

\section{Conclusion}

In this paper, a solid waste material of alumina industry, red mud, is processed to be used as an effective adsorbent for removal of phosphate. Red mud obtained from the alumina industry is treated with acid and heat and characterized

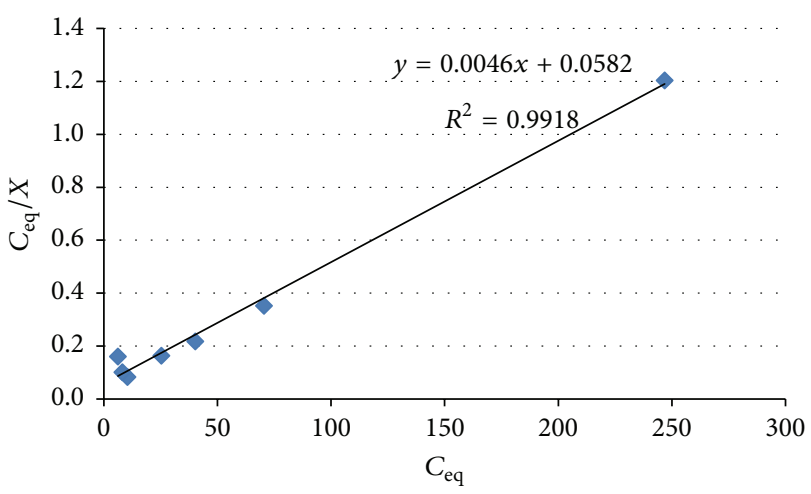

FIGURE 8: Langmuir plot of phosphate adsorption on acid treated activated red mud (RMA).

TABLE 3: The Langmuir parameter for all the RM samples.

\begin{tabular}{lcccc}
\hline S. number & Sample & $X(\mathrm{mg}$ P/g RM $)$ & $k$ & $R^{2}$ \\
\hline 1 & RM & 127.64 & 9.45 & 0.95 \\
2 & RMA & 205.13 & 12.65 & 0.99 \\
3 & RMH & 190.79 & 9.20 & 0.97 \\
4 & RMAH & 175.64 & 17.39 & 0.97 \\
\hline
\end{tabular}

using various modern characterization techniques. Characterization revealed the textural and phase change in the surface morphology resulting in the greater adsorption. The raw RM when treated with acid has shown a significant enhancement in the surface area and maximum adsorption achieved up to $205.13 \mathrm{mg}$ of $\mathrm{P} / \mathrm{g}$ of RM. Although the surface area of RMH and RMAH is greater than RMA, it shows a higher adsorption due to the fact that phosphate can also form chemisorbed complexes by ligand exchange reactions with hydroxide. Therefore, it is apparent that the adsorption phenomena do not depend solely on the surface area. The effects of variation in stirring time, phosphate concentration, adsorbent mass, and $\mathrm{pH}$ are studied and optimum conditions for adsorption of phosphate on RM are achieved. It is also found that Langmuir isotherm matched the experimental data. Therefore, the results indicate that the red mud can be effectively employed for the removal of phosphates and other anions from waste water or industrial effluents.

\section{Competing Interests}

The authors declare that there is no conflict of interests regarding the publication of this article.

\section{Acknowledgments}

The authors are thankful to NALCO, India, for providing the sample of red mud. One of the authors (Vijay M. Tangde) gratefully acknowledges the financial assistance received from Rashtrasant Tukadoji Maharaj Nagpur University, Nagpur, (no. Dev/1338 dt. 01/10/2014). 


\section{References}

[1] S. J. Shiao and K. Akashi, "Phosphate removal from aqueous solution from activated red mud," Journal of the Water Pollution Control Federation, vol. 49, no. 2, pp. 280-285, 1977.

[2] J. Pradhan, J. Das, S. Das, and R. S. Thakur, "Adsorption of phosphate from aqueous solution using activated red mud," Journal of Colloid and Interface Science, vol. 204, no. 1, pp. 169172, 1998.

[3] E. López, B. Soto, M. Arias, A. Núñez, D. Rubinos, and M. T. Barral, "Adsorbent properties of red mud and its use for wastewater treatment," Water Research, vol. 32, no. 4, pp. 13141322, 1998.

[4] H. S. Aitundogan and F. Tumen, "Removal of phosphates from aqueous solutions by using bauxite II: the activation study," Journal of Chemical Technology and Biotechnology, vol. 78, pp. 824-833, 2003.

[5] Y. Zhao, J. Wang, Z. Luan, X. Peng, Z. Liang, and L. Shi, "Removal of phosphate from aqueous solution by red mud using a factorial design," Journal of Hazardous Materials, vol. 165, no. 1-3, pp. 1193-1199, 2009.

[6] W. Huang, S. Wang, Z. Zhu et al., "Phosphate removal from wastewater using red mud," Journal of Hazardous Materials, vol. 158, no. 1, pp. 35-42, 2008.

[7] C.-J. Liu, Y.-Z. Li, Z.-K. Luan, Z.-Y. Chen, Z.-G. Zhang, and Z.P. Jia, "Adsorption removal of phosphate from aqueous solution by active red mud," Journal of Environmental Sciences, vol. 19, no. 10, pp. 1166-1170, 2007.

[8] S. Dursun, D. Guclu, and M. Bas, "Phosphate removal by using activated red mud from Seydisehir Aluminium Factory in Turkey," Journal of International Environmental Application \& Science, vol. 1, no. 3-4, pp. 98-106, 2006.

[9] J. Chen, H. Kong, D. Wu, Z. Hu, Z. Wang, and Y. Wang, "Removal of phosphate from aqueous solution by zeolite synthesized from fly ash," Journal of Colloid and Interface Science, vol. 300, no. 2, pp. 491-497, 2006.

[10] E. Oguz, "Sorption of phosphate from solid/liquid interface by fly ash," Colloids and Surfaces A: Physicochemical and Engineering Aspects, vol. 262, no. 1-3, pp. 113-117, 2005.

[11] N. M. Agyei, C. A. Strydom, and J. H. Potgieter, "The removal of phosphate ions from aqueous solution by fly ash, slag, ordinary Portland cement and related blends," Cement and Concrete Research, vol. 32, no. 12, pp. 1889-1897, 2002.

[12] N. M. Agyei, C. A. Strydom, and J. H. Potgieter, "An investigation of phosphate ion adsorption from aqueous solution by fly ash and slag," Cement and Concrete Research, vol. 30, no. 5, pp. 823-826, 2000.

[13] E. Galarneau and R. Gehr, "Phosphorus removal from wastewaters: experimental and theoretical support for alternative mechanisms," Water Research, vol. 31, no. 2, pp. 328-338, 1997.

[14] L. Wang, C. V. Putnis, E. Ruiz-Agudo, J. Hövelmann, and A. Putnis, "In situ imaging of interfacial precipitation of phosphate on goethite," Environmental Science and Technology, vol. 49, no. 7, pp. 4184-4192, 2015.

[15] C. Brunori, C. Cremisini, P. Massanisso, V. Pinto, and L. Torricelli, "Reuse of a treated red mud bauxite waste: studies on environmental compatibility," Journal of Hazardous Materials, vol. 117, no. 1, pp. 55-63, 2005.

[16] J. Pera, R. Boumaza, and J. Ambroise, "Development of a pozzolanic pigment from red mud," Cement and Concrete Research, vol. 27, no. 10, pp. 1513-1522, 1997.
[17] P. E. Tsakiridis, S. Agatzini-Leonardou, and P. Oustadakis, "Red mud addition in the raw meal for the production of Portland cement clinker," Journal of Hazardous Materials, vol. 116, no. 12, pp. 103-110, 2004.

[18] S. Zhang, C. Liu, Z. Luan, X. Peng, H. Ren, and J. Wang, "Arsenate removal from aqueous solutions using modified red mud," Journal of Hazardous Materials, vol. 152, no. 2, pp. 486492, 2008.

[19] H. Genç-Fuhrman, J. C. Tjell, and D. McConchie, "Increasing the arsenate adsorption capacity of neutralized red mud (Bauxsol)," Journal of Colloid and Interface Science, vol. 271, no. 2, pp. 313-320, 2004.

[20] H. S. Altundoğan, S. Altundoğan, F. Tümen, and M. Bildik, "Arsenic adsorption from aqueous solutions by activated red mud," Waste Management, vol. 22, no. 3, pp. 357-363, 2002.

[21] A. F. Bertocchi, M. Ghiani, R. Peretti, and A. Zucca, "Red mud and fly ash for remediation of mine sites contaminated with As, $\mathrm{Cd}, \mathrm{Cu}, \mathrm{Pb}$ and $\mathrm{Zn}$," Journal of Hazardous Materials, vol. 134, no. 1-3, pp. 112-119, 2006.

[22] C. Zhu, Z. Luan, Y. Wang, and X. Shan, "Removal of cadmium from aqueous solutions by adsorption on granular red mud (GRM)," Separation and Purification Technology, vol. 57, no. 1, pp. 161-169, 2007.

[23] M. Vaclavikova, P. Misaelides, G. Gallios, S. Jakabsky, and S. Hredzak, "Removal of cadmium, zinc, copper and lead by red mud, an iron oxides containing hydrometallurgical waste," Studies in Surface Science and Catalysis, vol. 155, pp. 517-525, 2005.

[24] J. Pradhan, S. N. Das, and R. S. Thakur, "Adsorption of hexavalent chromium from aqueous solution by using activated red mud," Journal of Colloid and Interface Science, vol. 217, no. 1, pp. 137-141, 1999.

[25] V. K. Gupta, M. K. Gupta, and S. Sharma, "Process development for the removal of lead and chromium from aqueous solutions using red mud-an aluminium industry waste," Water Research, vol. 35, no. 5, pp. 1125-1134, 2001.

[26] L. Santona, P. Castaldi, and P. Melis, "Evaluation of the interaction mechanisms between red muds and heavy metals," Journal of Hazardous Materials, vol. 136, no. 2, pp. 324-329, 2006.

[27] I. Mobasherpour, E. Salahi, and A. Asjodi, "Research on the batch and fixed column performance of red mud adsorbent for lead removal," Canadian Chemical Transactions, vol. 2, no. 1, pp. 83-96, 2014.

[28] V. V. Gurudic, S. Brasanac, L. Vesna, V. Pesic, and N. Z. Blagojevic, "Sorption of cadmium from water using neutralized red mud and activated neutralized red mud," ARPN Journal of Engineering and Applied Sciences, vol. 8, no. 11, pp. 933-943, 2013.

[29] S. B. Wang, Y. Boyjoo, A. Choueib, and Z. H. Zhu, "Removal of dyes from aqueous solution using fly ash and red mud," Water Research, vol. 39, no. 1, pp. 129-138, 2005.

[30] C. Namasivayam and D. J. S. E. Arasi, "Removal of congo red from wastewater by adsorption onto waste red mud," Chemosphere, vol. 34, no. 2, pp. 401-417, 1997.

[31] V. K. Gupta, I. Ali, and V. K. Saini, "Removal of chlorophenols from wastewater using red mud: an aluminum industry waste," Environmental Science and Technology, vol. 38, no. 14, pp. 40124018, 2004.

[32] V. K. Gupta, Suhas, I. Ali, and V. K. Saini, "Removal of rhodamine B, fast green, and methylene blue from wastewater using red mud, an aluminum industry waste," Industrial and 
Engineering Chemistry Research, vol. 43, no. 7, pp. 1740-1747, 2004.

[33] A. Tor, Y. Cengeloglu, M. E. Aydin, and M. Ersoz, "Removal of phenol from aqueous phase by using neutralized red mud," Journal of Colloid and Interface Science, vol. 300, no. 2, pp. 498503, 2006.

[34] C. Namasivayam and K. Thamaraiselvi, "Adsorption of 2chlorophenol by 'waste' red mud," Fresenius Environmental Bulletin, vol. 7, no. 5-6, pp. 314-319, 1998.

[35] M. S. Siboni, S.-J. Jafari, M. Farrokhi, and J. K. Yang, "Removal of phenol from aqueous solutions by activated red mud: equilibrium and kinetics studies," Environmental Engineering Research, vol. 18, no. 4, pp. 247-252, 2013.

[36] J. Murphy and J. P. Riley, "A modified single solution method for the determination of phosphate in natural waters," Analytica Chimica Acta, vol. 27, pp. 31-36, 1962.

[37] State Environmental Protection Adminstraion, Monitoring and Analysis Method of Water and Wastwater, vol. 7, Environmental Science Press, Beijing, China, 2002.

[38] R. J. Atkinson, A. M. Posner, and J. P. Quirk, "Kinetics of isotopic exchange of phosphate at the $\alpha$-FeOOH-aqueous solution interface," Journal of Inorganic and Nuclear Chemistry, vol. 34, no. 7, pp. 2201-2211, 1972.

[39] J. Kim, W. Li, B. L. Philips, and C. P. Grey, "Phosphate adsorption on the iron oxyhydroxides goethite $(\alpha-\mathrm{FeOOH})$, akaganeite $(\beta-\mathrm{FeOOH})$, and lepidocrocite $(\gamma-\mathrm{FeOOH}):{ }^{31} \mathrm{P}$ NMR study," Energy \& Environmental Science, vol. 4, no. 10, pp. 4298-4305, 2011. 

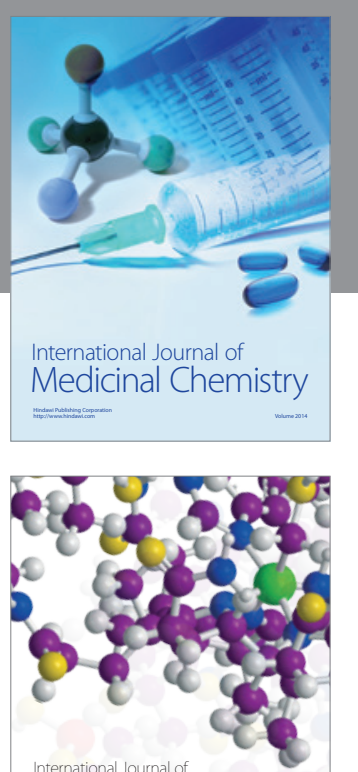

Carbohydrate Chemistry

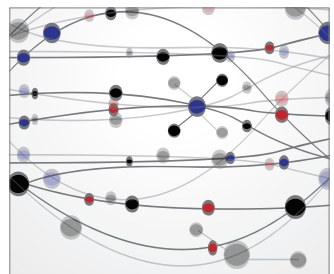

The Scientific World Journal
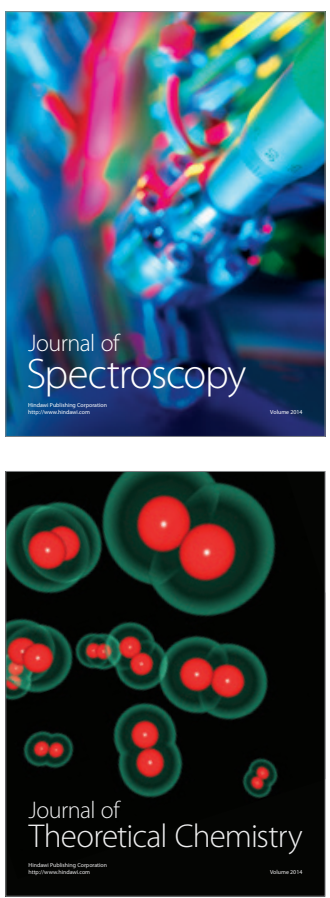
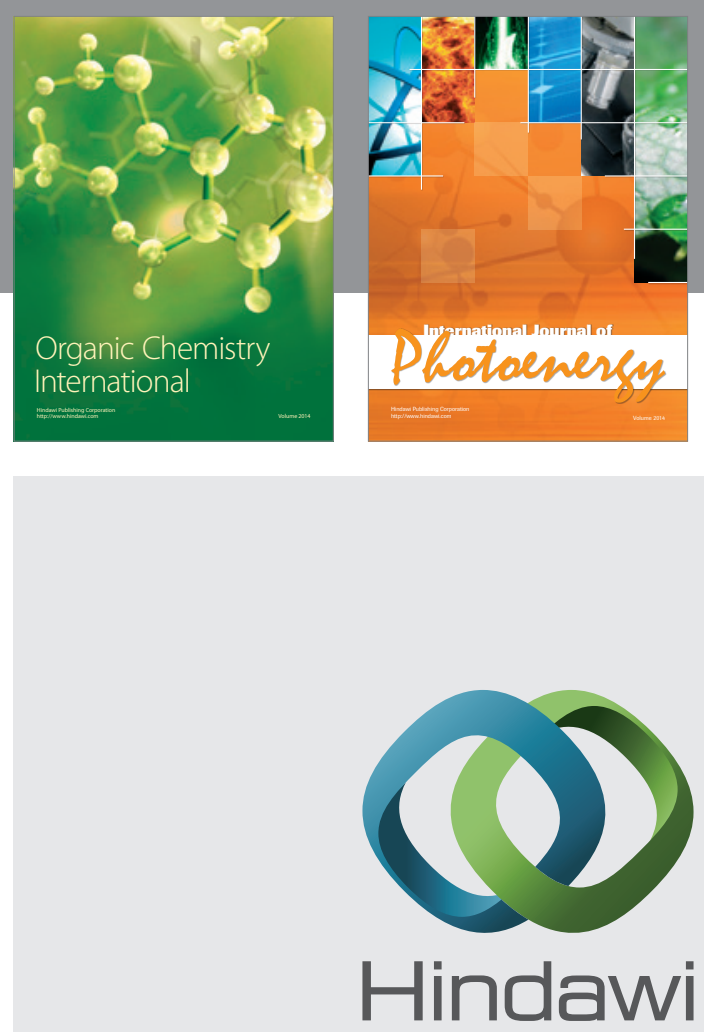

Submit your manuscripts at

http://www.hindawi.com

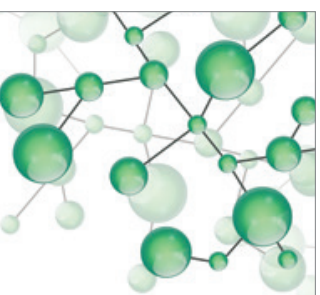

International Journal of

Inorganic Chemistry

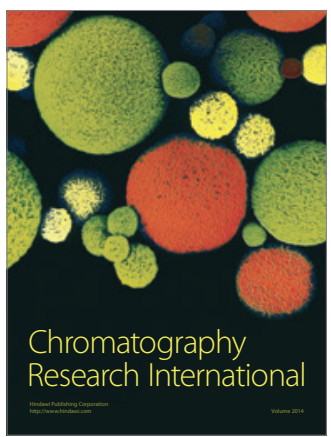

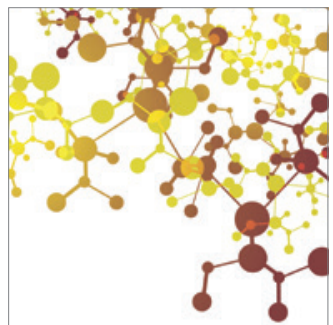

Applied Chemistry
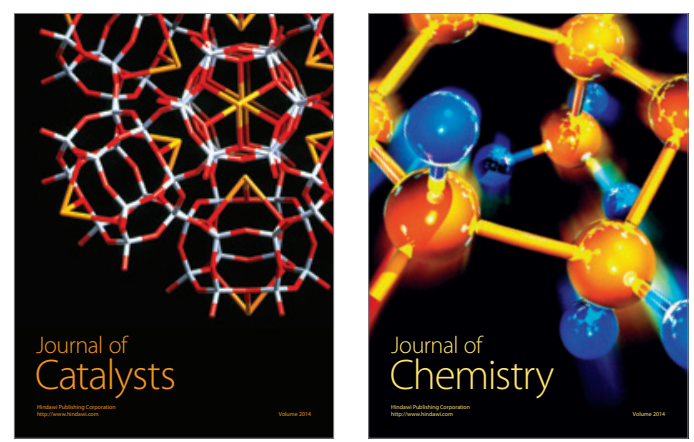
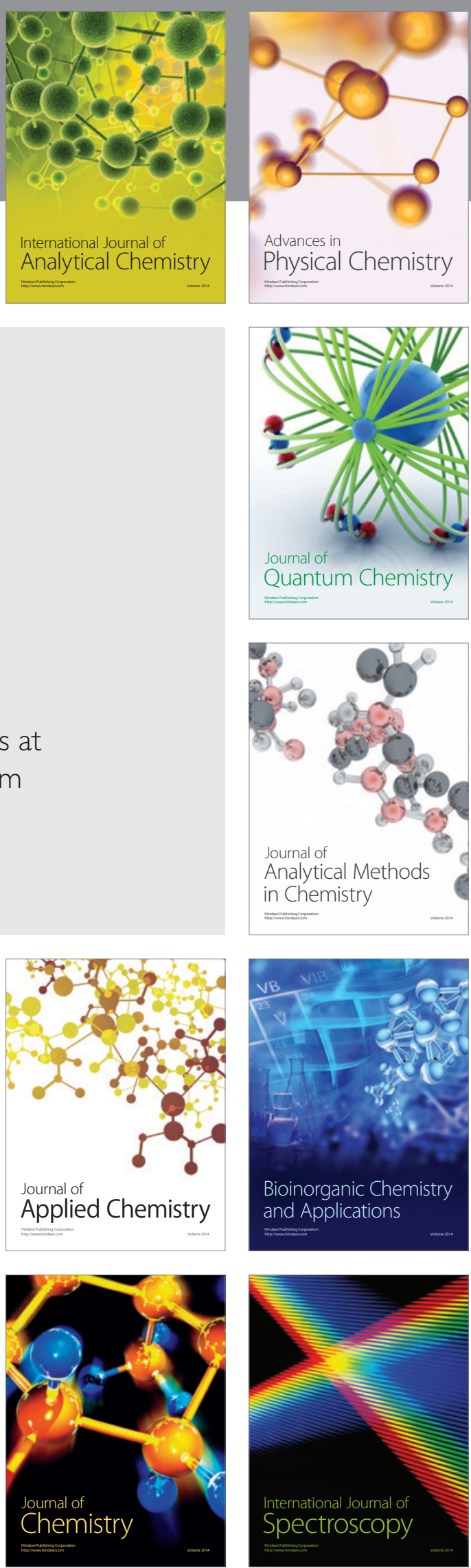